\title{
Nutritional Supplement for Athletic Performance: Based on Australian Institute of Sport Sports Supplement Framework
}

\section{Jooyoung Kim}

Department of Anatomy, School of Medicine, Kyungpook National University, Daegu, Korea

INTRODUCTION: Many athletes use nutritional supplements for their performance enhancements and training effects. However, it is unclear that some of the dietary supplements have favorable outcomes, and others may increase the risk of doping or side effects.

METHODS: In this review, we discuss the Australian Institute of Sport (AIS) Sports Supplement Framework's Group A performance supplements regarding safety, legality, and effectiveness in improving sports performance. Group A supplements include caffeine, betaalanine, bicarbonate, beetroot juice, creatine, and glycerol.

RESULTS: We found the use of these performance supplements could help athletes improve strength and endurance. However, the effects vary with individual athletes and depend on sports characteristics, training content, physical condition, and habits.

CONCLUSIONS: Therefore, a case-by-case approach is warranted to ensure their desirable effects. It is important to consult a doctor or sports nutritionist before consuming theses supplements and to monitor the individual's response through simulation.

Key words: Beetroot juice, Beta-alanine, Bicarbonate, Caffeine, Creatine, Glycerol

Introduction nutrition is essential for athletic performance, conditioning, and recovery from fatigue after exercise [1]. In this context, the use of nutritional supplements (also called ergogenic aids) is a matter of great interest for athletes. Although many nutritional supplements are used, there is debate about whether they actually have effects on athletes' performance, and several nutritional supplements are not sufficiently supported by scientific evidence [2]. Indeed, the use of some nutritional supplements is being stopped due to side effects or positive doping tests [3].

In order to reduce these issues, the Australian Institute of Sport (AIS) developed the Sports Supplement Framework. This classifies nutritional supplements into 4 groups (A, B, C, and D) based on scientific evidence, safety, legality, and effectiveness in improving sports performance. The nutritional supplements in Group A of the AIS Sports Supplement Framework possess strong scientific evidence and are permitted for athletes according to best practice protocols. This group includes sports food (sports drink, sports gel, sports bar, isolated protein supplement, etc.), medical supplements (iron, calcium, multivitamin, etc.), and perfor- mance supplements (caffeine, beta-alanine, bicarbonate, beetroot juice, creatine, and glycerol) [4].

The performance supplements in Group A are supported by sports nutrition expert groups and the latest literature [5-7]. In the International Society of Sports Nutrition (ISSN) exercise \& sports nutrition review, Kerksick et al. [6] report that there is strong evidence for the efficacy and safety of beta-alanine, caffeine, creatine, and bicarbonate, and in a consensus statement by the International Olympic Committee (IOC), Maughan et al. [7] included creatine, nitrate, bicarbonate, and beta-alanine as performance-enhancing supplements with an adequate level of support to indicate the potential for performance enhancement. Close et al. [5] classified performance supplements with strong evidence into those for endurance (caffeine, beta-alanine, beetroot juice, bicarbonate) and those for strength/size (creatine). In summary, in order for athletes to safely and effectively utilize performance supplements in competition and training, it is important to investigate the level of scientific evidence.

Group B of the AIS Sports Supplement Framework includes food

Corresponding author: Jooyoung Kim Tel +82-53-420-4910 Fax +82-53-422-9195 E-mail hirase1125ahanmail.net

Received 2 Jun 2019 Revised 22 Jul 2019 Accepted 29 Jul 2019

(a) This is an Open Access article distributed under the terms of the Creative Commons Attribution Non-Commercial License (http://creativecommons.org/licenses/by-nc/4.0/) which permits unrestricted non-commercial use, distribution, and reproduction in any medium, provided the original work is properly cited. 
polyphenols (cherries, berried, quercitin, epigallocatechin gallate, etc.), other (collagen support, carnitine, $\beta$-Hydroxy $\beta$-methylbutyric acid, fish oils, etc.), sick pack (zinc lozenges and vitamin C), and amino acids (branched-chain amino acids and leucine). Group C contains all other nutritional supplements that are not found in Groups A or B. Finally, Group D contains substances banned by the World Anti-Doping Agency (WADA), such as stimulants (ephedrine, strychnine, sibutramine, etc.) and prohormones and hormone boosters (dehydroepiandrosterone, androstenedione, 19-norandrostenione/ol, etc.) [4].

The purpose of our study is to enable coaches, trainers, and athletes to safely and effectively utilize caffeine, beta-alanine, bicarbonate, beetroot juice, creatine, and glycerol, which are included in the Group A perfor- mance supplements in the AIS Sports Supplement Framework, by providing information about their effectiveness and recommendations.

\section{PERFORMANCE SUPPLEMENTS}

\section{Caffeine}

Caffeine (1, 3, 7-trimethylxanthine) is a major component of tea, coffee, guarana, and cacao [8]; it is a pharmacologic and psychoactive substance that is consumed frequently worldwide [9]. In sports, caffeine is a well known nutritional supplement, and has been actively studied since the 1970s [10].

Generally, caffeine helps to improve endurance, strength, and power

Table 1. Recommendations for performance supplements

\begin{tabular}{|c|c|}
\hline $\begin{array}{l}\text { Performance } \\
\text { Supplements }\end{array}$ & Recommendations \\
\hline Caffeine & $\begin{array}{l}\text { - The dose of caffeine should be in the range 3-6 mg/kg b.w. High doses, such as } 9 \mathrm{mg} / \mathrm{kg} \text { b.w. may be ineffective [16,17]. } \\
\text { - Caffeine can be consumed as coffee, in an anhydrous state (capsule/tablet, powder), or as chewing gum [17,24,25]. } \\
\text { - A single can of caffeine-containing energy drink does not provide the required caffeine dose [22,23]. } \\
\text { - Good timing for caffeine intake is } 60 \text { minutes before competition or training [17]. } \\
\text { - Potential side effect: headaches, gastrointestinal upset, nervousness, mental confusion, and disturbed sleeping [10]. }\end{array}$ \\
\hline Beta-alanine & $\begin{array}{l}\text { - To improve athletic performance, beta-alanine should be taken for at least 2-4 weeks [26]. } \\
\text { - Beta-alanine can generally be consumed within a range of } 4-6 \mathrm{~g} / \text { day }[26] . \\
\text { - If symptoms such as paresthesia develop after taking beta-alanine, intake can be split across several doses per day (e.g., 1.6 g doses) [26]. } \\
\text { - Beta-alanine can be taken after a meal at breakfast, lunch, and dinner [35,36]. }\end{array}$ \\
\hline Bicarbonate & $\begin{array}{l}\text { - In bicarbonate supplementation, it is effective to use a loading protocol to increase serum bicarbonate concentration and buffering ca- } \\
\begin{array}{l}\text { pacity [45,46]. } \\
\text { - Loading protocols } \\
\text { Acute loading: } 0.3 \mathrm{~g} / \mathrm{kg} \text { b.w., taken 1-3 hours before competition or training [45]. } \\
\text { Serial loading: } 0.3-0.5 \mathrm{~g} / \mathrm{kg} \text { b.w. (divided into 3-4 doses/day), taken for 3-5 days before competition } \\
\text { or training }[46] .\end{array} \\
\begin{array}{l}\text { - During bicarbonate supplementation, side effects, such as gastrointestinal distress, can be reduced by methods such as multiday in- } \\
\text { gestion, chronic progressive-dose, or split-dose protocols }[47,48] .\end{array}\end{array}$ \\
\hline Beetroot juice & $\begin{array}{l}\text { - Beetroot juice can be consumed } 90 \text { minutes before competition or training [50]. } \\
\text { - Beetroot juice can be consumed at a dose of } 500 \mathrm{~mL} / \text { day (around } 2 \text { cups) (the beetroot juice should contain 5-8.4 mmol nitrate) [55,58]. } \\
\text { - Both acute (single dose) and chronic (doses for 6-7 days) beetroot juice intake are effective at improving exercise performance [60,61]. } \\
\text { - If beetroot juice is consumed, oral antiseptic rinses should be avoided [50]. } \\
\text { - No side effects have been reported. }\end{array}$ \\
\hline Creatine & $\begin{array}{l}\text { - Creatine loading is generally proposed to increase intramuscular creatine capacity. Creatine loading consists of a loading phase (0.3 g/kg } \\
\text { b.w. or 20-30 g/day, divided into 3-4 doses/day, for 3-5 days) and a maintain phase (3-5 g/day after the loading phase) [72]. } \\
\text { - A small amount of creatine (3-5 g/day) can be taken from the start, without creatine loading [63]. } \\
\text { - During creatine intake, it is still not clear whether a washout phase is required. More scientific evidence is required in this area [74,75]. } \\
\text { - Creatine can be taken in a mixture together with carbohydrates or carbohydrates and proteins [76]. } \\
\text { - In terms of timing for creatine intake, post-exercise intake is more effective than pre-exercise intake [78,79]. } \\
\text { - Potential side effect: dehydration, muscle cramping, and gastrointestinal upset [63]. }\end{array}$ \\
\hline \multirow[t]{4}{*}{ Glycerol } & $\begin{array}{l}\text { - Glycerol intake can help to prevent dehydration and improve endurance performance during competition or training in high-tempera- } \\
\text { ture environments [89-91]. } \\
\text { - Glycerol can be take before or during exercise. Refer to the protocols below }[87,92,93] \text {. }\end{array}$ \\
\hline & $\begin{array}{l}\text { - Protocols for glycerol intake } \quad \begin{array}{l}\text { Pre-exercise: It is recommended to take } 1.2 \mathrm{~g} / \mathrm{kg} \text { b.w. of glycerol with } 26 \mathrm{~mL} / \mathrm{kg} \text { b.w. of fluid during } \\
60 \text { minutes [86]. } \\
\text { During exercise: If glycerol was taken pre-exercise, } 0.125 \mathrm{~g} / \mathrm{kg} \mathrm{b.w.} \mathrm{of} \mathrm{glycerol} \mathrm{should} \mathrm{be} \mathrm{taken} \mathrm{with} \\
5 \mathrm{~mL} / \mathrm{kg} \text { b.w. of fluid; if glycerol was not taken pre-exercise, } 0.4 \mathrm{~g} / \mathrm{kg} \text { b.w. of glycerol should be } \\
\text { taken with fluid during each of the first } 4 \text { hours of exercise [85]. }\end{array}\end{array}$ \\
\hline & ctrolyte sports drink [88]. \\
\hline & - Potential side effect: nausea, gastrointestinal discomfort, dizziness, and headaches [85]. \\
\hline
\end{tabular}


by activating various biologic mechanisms [11]. Caffeine stimulates the sympathetic nervous system and increases the blood epinephrine concentration, promoting lipolysis of adipose and intramuscular triglycerides. These changes conserve stored glycogen and improve endurance performance. This is referred to as the glycogen sparing effect [8]. Potgieter et al. [11] reported that $6 \mathrm{mg} / \mathrm{kg}$ body weight (b.w.) of caffeine intake before exercise reduced swim time and time to completion by $3.7 \%$ and $1.3 \%$, respectively, in triathletes. Felippe et al. [12] reported that $5 \mathrm{mg} / \mathrm{kg}$ b.w. of caffeine intake before exercise resulted in faster 4-km cycling time trials in cyclists.

Caffeine is able to help improve strength and power because it increases the intracellular $\mathrm{Ca}^{2+}$ concentration by stimulating the sarcoplasmic reticulum in muscle fibers, while also affecting excitation-contraction coupling by inhibiting uptake [13]. In fact, Diaz-Lara et al. [14] reported that Jiu-jitsu athletes who took caffeine before exercise showed improved hand grip force, countermovement jump height, one-repetition maximum, and mean power during the bench-press exercise, and Glaister et al. [15] reported that pre-exercise caffeine intake significantly improves peak anaerobic power output in well-trained men.

In terms of practical applications for athletic performance, factors such as dose, form, and timing can be considered (Table 1). A caffeine dose of 3-6 mg/kg b.w. is recommended [16,17]. Recently Chia et al. [18] reported that intake of 3-6 mg/kg b.w. of caffeine appears to be a safe ergogenic aid for ball game athletes. However, doses of caffeine over $9 \mathrm{mg} /$ $\mathrm{kg}$ b.w. show no beneficial effects, and can actually decrease performance level [19]. It has been reported that caffeine produces a stronger effect when consumed in an anhydrous state (capsule/tablet, powder) compared to coffee [17], but if the dose is sufficient, pre-exercise caffeine intake is effective at improving endurance performance in either state [20,21]. Several studies have reported that caffeine-containing energy drinks help to improve athletes' performance $[22,23]$. Although some athletes have tried consuming caffeine in energy drinks, it is important to be aware that one can does not provide the recommended caffeine intake for athletes. For example, the caffeine content in a single can (250 $\mathrm{mL}$ ) of the well-known energy drink 'Red Bull' is only $80 \mathrm{mg}$. In actual research, athletes consumed $3 \mathrm{mg} / \mathrm{kg}$ b.w. of caffeine from energy drinks, not just a single can $[22,23]$. In order to satisfy the caffeine intake suggested in these studies, the athlete needs to drink several cans, and this requires caution as it could promote weight gain due to unnecessary calorie and carbohydrate intake.

In recent studies, caffeine chewing gum (300 mg of caffeine) was also reported to help improve muscle function, such as vertical jump height and knee extension peak torque [24], as well as exercise tolerance [25]. Meanwhile, with regard to the timing of intake, most studies suggested a protocol for caffeine intake 60 minutes before exercise for optimum absorption [17]. In addition, caffeine is quickly absorbed into the body after ingestion. The peak of the blood concentration is shown to be around 30 to 60 minutes after ingestion [19].

\section{Beta-alanine}

Beta-alanine is a non-essential and non-proteinogenic amino acid synthesized by the liver, and can also be obtained from foods such as pork, chicken, or red meat [26]. The main aim of beta-alanine supplementation is to increase intramuscular carnosine (b-alanyl-L-histidine). Carnosine is a cytoplasmic dipeptide formed when carnosine synthetase catalyzed the formation of peptide bond between beta-alanine and $\mathrm{L}$ histidine; carnosine is found in many tissues in the body, but mostly is present in skeletal muscle [27]. In normal conditions, beta-alanine production is relatively low and serum beta-alanine is undetectable, but when serum beta-alanine increases to detectable levels, intramuscular carnosine levels are known to also increase [28]. Carnosine synthesis is controlled by the rate and amount of beta-alanine absorption into muscle fibers, insufficient serum carnosine synthetase activity, beta-alanine content in food, and hepatic synthesis of amino acids and their transport to skeletal muscles $[29,30]$. When beta-alanine is supplemented, 1) betaalanine moves into the blood stream via the gastrointestinal tract, 2) beta-alanine and histidine are transported into the muscle sarcoplasm by amino acid transporters, 3) beta-alanine and histidine are bonded together in the muscle sarcoplasm by carnosine synthetase to produce carnosine [31].

Increased carnosine can improve performance during exercise by buffering hydrogen ion $\left(\mathrm{H}^{+}\right)$accumulation, limiting the effects of metabolic acidosis such as reduced phosphofructokinase activity, phosphocreatine resynthesis and glycolysis inhibition, and competitive inhibition of $\mathrm{Ca}^{2+}$ at troponin $\mathrm{C}$ and delayed $\mathrm{Ca}^{2+}$ reuptake to the sarcoplasmic reticulum [32]. Thus, it has also been suggested that the improvements in muscle strength, power, and endurance following beta-alanine supplementation are due to increased muscle fiber sensitivity to $\mathrm{Ca}^{2+}$ and the resulting enhancement in excitation-contraction coupling [26]. In practice, Baguet et al. [33] observed increased carnosine concentration in the soleus and gastrocnemius after elite rowers consumed $5 \mathrm{~g}$ /day of beta-alanine for 7 weeks, and reported that these changes were positively correlated with 
rowing performance. Saunders et al. [34] also had soccer players consume $3.2 \mathrm{~g} /$ day of beta-alanine for 12 weeks, and reported significant improvements in Yo-Yo Intermittent Recovery test (Yo-Yo IR) times.

In order to significantly increase intramuscular carnosine levels, 4-6 $\mathrm{g} /$ day of beta-alanine should be consumed for at least 2-4 weeks, and 4-6 $\mathrm{g} /$ day of beta-alanine intake is safe for healthy individuals [26] (Table 1). The optimal timing for beta-alanine intake is not yet well known. With reference to previous studies, beta-alanine has been taken after each meal (morning, lunch, and dinner) [35,36]. Adverse events have not commonly been reported after beta-alanine supplementation, but paresthesia can occur [37]. However, when beta-alanine intake is divided across several small doses (1.6 g/dose) rather than one large dose, paresthesia can be reduced [26].

\section{Bicarbonate}

Bicarbonate $\left(\mathrm{HCO}^{3-}\right)$ is an extracellular anion that plays an important role in maintaining extracellular and intracellular $\mathrm{pH}$ [38]. In humans at rest, the blood is slightly alkaline ( $\mathrm{pH} \sim 7.4$ ) while the muscles are neutral ( $\mathrm{pH} ~ 7.0)$, and this acid-base balance in the blood and muscle is important for normal cell metabolism [39]. However, during high-intensity exercise, acidification of cells occurs. This change interferes with muscle contraction through negative effects on myosin ATPase, $\mathrm{Ca}^{2+}$ ATPase, and $\mathrm{Na}^{+}-\mathrm{K}^{+}$ATPase activity, weakens $\mathrm{K}^{+}$efflux through $\mathrm{pH}$-sensitive potassium channels, and impairs the activity of metabolic enzymes [40]. It also decreases energy production by lowering the proton gradient between the mitochondrial matrix and the cell cytoplasm [41].

When bicarbonate is supplemented, bicarbonate loading prevents the accumulation of $\mathrm{H}^{+}$, which is over-produced by the anaerobic energy metabolism used in short-duration, high-intensity exercise, which delays fatigue and allows energy production to continue, ultimately contributing to improved exercise performance [42]. In other words, bicarbonate has a similar mechanism and effect to those of beta-alanine, discussed above. Krustrup et al. [40] analyzed the serum $\mathrm{pH}$ after giving trained young men bicarbonate supplement, and observed higher serum $\mathrm{pH}$ than a control group, accompanied by significantly improved high-intensity intermittent exercise performance. Likewise, Wu et al. [43] reported that bicarbonate supplementation in tennis players resulted in higher blood $\mathrm{pH}$, and helped to maintain service and forehand ground stroke consistency scores. Lopes-Silva et al. [44] reported that, when bicarbonate supplementation was provided to taekwondo athletes, glycolytic energy contribution increased in the first round of simulated tae- kwondo combat, resulting in improved exercise performance.

Bicarbonate supplementation needs to occur at the appropriate time before exercise, and a loading protocol should be utilized, as this can increase the serum bicarbonate concentration and the buffering capacity. Bicarbonate supplementation can use acute loading or serial loading methods (Table 1). For acute loading, Price \& Singh [45] reported that bicarbonate needs to be taken 1-3 hours before exercise in order to significantly increase serum bicarbonate levels, and Lopes-Silva et al. [44] reported that $0.3 \mathrm{~g} / \mathrm{kg}$ b.w. should typically be taken before exercise. Serial loading, which is the method of taking bicarbonate several times per day for several days, involves 3-4 doses/day of 0.3-0.5 g/kg b.w. for 3-5 days before competition or training [46].

The main reported side effect of bicarbonate is gastrointestinal distress including nausea, stomach pain, diarrhea and vomiting [42]. In order to reduce these side-effects, methods such as multiday ingestion, chronic progressive-dose, and split-dose protocols have been suggested [47,48]. For example, recently, Durkalec-Michalski et al. [47] provided progressive supplementation of bicarbonate to wrestlers for 10 days, starting from a dose of $25 \mathrm{mg} / \mathrm{kg}$ b.w. up to a dose of $100 \mathrm{mg} / \mathrm{kg}$ b.w., and reported that this was effective at eliminating side effects, including gastrointestinal symptoms.

\section{Beetroot juice}

Beetroot (Beta vulgaris) juice is a natural food and nutritional supplement that has recently been receiving much attention from athletes and sports scientists in the field of sports nutrition. Beetroot is known to be abundant in antioxidants and micronutrients such as potassium, betaine, sodium, magnesium, and vitamin C [49]. Most importantly, beetroot is a source of nitrate [50]. Nitrate is a naturally existing inorganic polyatomic anion [49]. When nitrate enters the mouth, it is actively extracted and concentrated from the saliva and reduced to nitrite by bacteria; in the stomach, nitrite is further reduced, and eventually converted into nitric oxide (NO) in the muscle [51]. Therefore, nitrate that is supplemented through beetroot juice can be considered a precursor of $\mathrm{NO}$, and NO contributes to various physiological functions, including vasodilation, mitochondrial respiration, biogenesis, muscle glucose uptake, angiogenesis, and sarcoplasmic reticulum calcium handling [52]. Furthermore, $\mathrm{NO}$ can improve exercise tolerance while reducing muscle metabolic perturbation (reduction of phosphocreatine and accumulation of adenosine diphosphate and $\mathrm{Pi}$ ) that occurs during high-intensity exercise [53]. 
Several studies have reported that beetroot juice produces significant changes in athletic performance [54-57]. Lansley et al. [55] reported that beetroot juice intake significantly improved power output and $16.1-\mathrm{km}$ cycling time trials in competitive male cyclists, and Cuenca et al. [54] reported that beetroot juice intake significant improved 30-second cycling sprint performance in resistance-trained men. Thompson et al. [56] reported that nitrate supplementation by beetroot juice improved sprint split times and also Yo-Yo IR performance in team-sport players. Wylie et al. [57] reported that nitrate-rich beetroot juice intake helped recreational team-sport players to better maintain muscle glucose uptake and muscle excitability while improving Yo-Yo IR performance. In summary, beetroot juice intake has been found to be effective at improving power exercise, high-intensity intermittent exercise, and endurance performance.

In order for athletes to benefit from the effects of beetroot juice, several protocols need to be considered from previous study (Table 1). First, the appropriate time for beetroot juice intake is approximately $90 \mathrm{~min}$ utes before competition. The peak nitrate concentration occurs 2-3 hours after beetroot juice intake [50]. It is recommended to consume $500 \mathrm{~mL} /$ day (approximately 2 cups) of beetroot juice containing 5-8.4 mmol nitrate $[55,58]$. According to previous studies, a single dose of beetroot juice produces an acute effect $[55,59]$, and consuming beetroot juice for 6-7 days also has a positive effect on exercise performance $[60,61]$. Finally, when consuming beetroot juice, oral antiseptic rinses should be avoided. This is because oral antiseptic rinses inhibit the conversion of nitrate from beetroot juice to nitrite in the mouth [50].

\section{Creatine}

Creatine is an amino acid that is synthesized in the liver, kidney, and pancreas, can be found in high levels in the musculoskeletal system, and can also be obtained naturally by consuming fish or meat [62]. Creatine is currently the most effective ergogenic nutritional supplement that can be used to increase high-intensity exercise ability and lean mass [63]. In many studies, creatine supplementation has been reported to increase intramuscular phosphocreatine concentration and high-energy phosphate metabolism, helping to improve exercise performance, including muscle strength [64-66]. In addition, creatine increases calcium re-uptake into the sarcoplasmic reticulum, enabling rapid detachment of actin-myosin cross-bridges and augmenting the latent force-generating capacity [67]. Creatine also increases water retention by cells [68]. Increased cell size due to creatine-induced water retention is associated with upregulation of signaling pathways that mediate protein synthesis, as well as mechanistic target of rapamycin (mTOR)-mediated signaling [69,70]. These changes help muscle hypertrophy by both stimulating muscle protein synthesis and reducing breakdown [71].

Creatine is typically taken in a loading phase $(0.3 \mathrm{~g} / \mathrm{kg}$ b.w. or $20-30 \mathrm{~g} /$ day, divided into 3-4 doses/day, for 3-5 days) and a maintain phase (3-5 g/day after the loading phase) [72] (Table 1). This method is called 'creatine loading', and is the optimal method to increase the intramuscular creatine capacity [73]. Creatine can be taken in small amounts (3-5 g/ day) from the start, without a loading phase, but the initial enhancement of exercise performance is better if a loading phase is included [63]. In some studies, long-term intake for at least 3 months could cause downregulation of creatine transporter [74,75], and so it has been suggested that a washout phase is necessary. However, there is still a shortage of clear evidence for this hypothesis, and further research is required Alongside creatine loading, it is recommended that creatine should be taken in a mixture with carbohydrates or carbohydrates and proteins [76], since this can promote insulin stimulation [77].

In terms of the timing of creatine intake, post-exercise is recommended more than pre-exercise $[78,79]$. Antonio \& Ciccone [78] reported that when creatine was given before or after resistance exercise, post-exercise supplementation had greater positive effects on body composition and strength; Candow et al. [79] also reported that creatine supplementation after resistance exercise resulted in greater augmentation of muscle accretion and lean tissue mass. One possible reason why post-exercise creatine intake could be more effective is because creatine transport and accumulation is increased due to higher muscle blood glow and $\mathrm{Na}^{+}-\mathrm{K}^{+}$ pump function $[80,81]$.

On the other hand, creatine is not a suitable nutritional supplement for athletes trying to improve aerobic performance [82]. This is because aerobic metabolism is affected by triglycerides rather than PCR [83].

\section{Glycerol}

Glycerol (1, 2, 3-propanetriol) is produced from glucose, protein, pyruvate, triacylglycerols and other glycerolipid metabolic pathways [84]. The function of glycerol is to maintain hydration status by increasing water compartments in the body. The aim of glycerol supplementation is to create a state of hyperhydration pre-exercise, delays fluid loss and dehydration during exercise, and improve the rate of rehydration and total fluid retention post-exercise [85]. Although maintaining hydration status pre-exercise is important to improve athletic performance, it is difficult to drink a large volume of water at once, and this can cause side effects 
such as frequent diuresis [86]. Glycerol can be supplemented to reduce these issues. Compared to water intake only, glycerol supplementation increased fluid retention by 400-1,000 mL [87]. For this reason glycerol is currently sold as a sports supplement for water or sports drink consumption [88].

Glycerol supplementation can be especially effective when exercising in high-temperature environments [89-91]. According to a study by van Rosendal et al. [90], when endurance-trained men received intravenous fluids and glycerol supplementation, plasma volume restoration increased. Wingo et al. [91], administered a water and glycerol mixture to male mountain bikers, and observed less dehydration compared in a high-temperature environment compared to water alone, lower pre-exercise urine volume, and lower post-exercise environmental symptoms questionnaire scores. Lyons et al. [89] also administered a mixture of water and glycerol, and reported increased sweat rate and decreased rectal temperature during exercise, resulting in reduced thermal burden in a high-temperature environment. This changes are ultimately linked to improvements in exercise performance, especially endurance performance. van Rosendal et al. [85] reported that glycerol supplementation increased endurance time to exhaustion up to $25 \%$. During exercise after glycerol supplementation, fluid retention helps to reduce dehydration and cardiovascular strain while improving endurance performance. According to a study by Montner et al. [92], pre-exercise glycerol-enhanced hyperhydration reduced heart rate and increased endurance time.

Generally, glycerol is used before and during exercise [87,92,93] (Table 1). Pre-exercise, it is recommended to take $1.2 \mathrm{~g} / \mathrm{kg}$ b.w. of glycerol together with $26 \mathrm{~mL} / \mathrm{kg}$ b.w. of fluid in 60 minutes [86]. During exercise, the glycerol supplementation method is as follows: if glycerol was taken pre-exercise, $0.125 \mathrm{~g} / \mathrm{kg}$ b.w. of glycerol should be taken with $5 \mathrm{~mL} / \mathrm{kg}$ b.w. of fluid; if glycerol was not take pre-exercise, athletes should take 0.4 $\mathrm{g} / \mathrm{kg}$ b.w. of glycerol with fluid during each of the first 4 hours of exercise [85]. Although rare, side-effects during glycerol supplementation can include nausea, gastrointestinal discomfort, dizziness, and headaches [94]. If an athlete develops these symptoms, they should stop taking glycerol or reduce the dose [85].

\section{CONCLUSION}

In sports, even a small improvement in performance can make a very important difference. Athletes choose and consume performance supplements for these small differences. In this study, we reviewed caffeine, beta-alanine, bicarbonate, beetroot juice, creatine, and glycerol, which are included in Group A performance supplements in the AIS Sports Supplement Framework. Our review of the literature showed that appropriate use of these performance supplements can help to improve athletes' strength or endurance. However, it is essential for athletes, coaches, and trainers to understand that the effects of performance supplements show considerable inter-subject variability, and since there may be differences in the sport characteristics, training content, physical condition, and habits, a case-by-case approach is required. Thus, it is important to assess the risk-benefit ratio of performance supplements, and before use, a specialist (doctor or sports nutritionist) should be consulted, and the individual's response should be monitored through simulation in a similar environment to competition or training.

Before using performance supplements, athletes should ask themselves several questions. An IOC consensus statement published in 2018 provided a flow chart to guide informed decision-making regarding ergogenic supplement use and reduce the risk of antidoping rule violations. This flow chart contains a sequence of questions such as 'Is the athlete ready for supplement use?', 'Should I use this supplement?', 'Is supplement effective in my event?', 'Is it safe for me to use?', 'Supplement comes from a reliable source?', and 'Consistent positive results?'; after going through these questions, if the response is 'No/Not known', the supplement should not be used [7]. Athletes should always be cautious about indiscriminate use of performance supplements, and be aware of the potential risks.

\section{CONFLICT OF INTEREST}

No potential conflict of interest relevant to this article was reported.

\section{REFERENCE}

1. Aoi W, Naito Y, Yoshikawa T. Exercise and functional foods. Nutr J. 2006;5:15.

2. Sousa M, Fernandes MJ, Carvalho P, Soares J, Moreira P, et al. Nutritional supplements use in high-performance athletes is related with lower nutritional inadequacy from food. J Sport Health Sci. 2016; 5(3):368-74.

3. Petróczi A, Naughton DP, Mazanov J, Holloway A, Bingham J. Performance enhancement with supplements: incongruence between rationale and practice. J Int Soc Sports Nutr. 2007;4:19. 
4. Australian Institute of Sport (AIS). The AIS Sports Supplement Framework. 2019 March; Retrieved from https://www.sportaus.gov. $\mathrm{au} /$ ais/nutrition/supplements

5. Close GL, Hamilton DL, Philp A, Burke LM, Morton JP. New strategies in sport nutrition to increase exercise performance. Free Radic Biol Med. 2016;98:144-58.

6. Kerksick CM, Wilborn CD, Roberts MD, Smith-Ryan A, Kleiner SM, et al. ISSN exercise \& sports nutrition review update: research \& recommendations. J Int Soc Sports Nutr. 2018;15(1):38.

7. Maughan RJ, Burke LM, Dvorak J, Larson-Meyer DE, Peeling P, et al. IOC consensus statement: dietary supplements and the high-performance athlete. Br J Sports Med. 2018;52(7):439-55.

8. Graham TE. Caffeine and exercise: metabolism, endurance and performance. Sports Med. 2001;31(11):785-807.

9. Cappelletti S, Piacentino D, Sani G, Aromatario M. Caffeine: cognitive and physical performance enhancer or psychoactive drug? Curr Neuropharmacol. 2015;13(1):71-88.

10. Spriet LL. Exercise and sport performance with low doses of caffeine. Sports Med. 2014;2:175-84.

11. Potgieter S, Wright HH, Smith C. Caffeine improves triathlon performance: a field study in males and females. Int J Sport Nutr Exerc Metab. 2018;28(3):228-37.

12. Felippe LC, Ferreira G, Learsi SK, Boari D, Bertuzzi R, et al. Caffeine increases both total work performed above critical power and peripheral fatigue during a 4-km cycling time trial. J Appl Physiol. 2018; 124(6):1491-501.

13. Wilk M, Krzysztofik M, Maszczyk A, Chycki J, Zajac A. The acute effects of caffeine intake on time under tension and power generated during the bench press movement. J Int Soc Sports Nutr. 2019;16(1):8.

14. Diaz-Lara FJ, Del Coso J, García JM, Portillo LJ, Areces F, et al. Caffeine improves muscular performance in elite Brazilian Jiu-jitsu athletes. Eur J Sport Sci. 2016;16(8):1079-86.

15. Glaister M, Muniz-Pumares D, Patterson SD, Foley P, McInnes G. Caffeine supplementation and peak anaerobic power output. Eur J Sport Sci. 2015;15(5):400-6.

16. Campbell B, Wilborn C, La Bounty P, Taylor L, Nelson MT, et al. International Society of Sports Nutrition position stand: energy drinks. J Int Soc Sports Nutr. 2013;10(1):1.

17. Goldstein ER, Ziegenfuss T, Kalman D, Kreider R, Campbell B, et al. International society of sports nutrition position stand: caffeine and performance. J Int Soc Sports Nutr. 2010;7(1):5.
18. Chia JS, Barrett LA, Chow JY, Burns SF. Effects of caffeine supplementation on performance in ball games. Sports Med. 2017;47(12):245371.

19. Sökmen B, Armstrong LE, Kraemer WJ, Casa DJ, Dias JC, et al. Caffeine use in sports: considerations for the athlete. J Strength Cond Res. 2008;22(3):978-86.

20. Hodgson AB, Randell RK, Jeukendrup AE. The metabolic and performance effects of caffeine compared to coffee during endurance exercise. PLoS One. 2013;8(4):e59561.

21. Bello ML, Walker AJ, McFadden BA, Sanders DJ, Arent SM. The effects of TeaCrine ${ }^{\circledR}$ and caffeine on endurance and cognitive performance during a simulated match in high-level soccer players. J Int Soc Sports Nutr. 2019;16(1):20.

22. Abian-Vicen J, Puente C, Salinero JJ, González-Millán C, Areces F, et al. A caffeinated energy drink improves jump performance in adolescent basketball players. Amino Acids. 2014;46(5):1333-41.

23. Lara B, Gonzalez-Millán C, Salinero JJ, Abian-Vicen J, Areces F, et al Caffeine-containing energy drink improves physical performance in female soccer players. Amino Acids. 2014;46(5):1385-92.

24. Veiner S, Grgic J, Mikulic P. Acute enhancement of jump performance, muscle strength, and power in resistance-trained men after consumption of caffeinated chewing gum. Int J Sports Physiol Perform. 2019:123.

25. Dittrich N, Serpa MC, Lemos EC, De Lucas RD, Guglielmo LGA. Effects of caffeine chewing gum on exercise tolerance and neuromuscular responses in well-trained runners. J Strength Cond Res. 2019.

26. Trexler ET, Smith-Ryan AE, Stout JR, Hoffman JR, Wilborn CD, et al. International society of sports nutrition position stand: Beta-Alanine. J Int Soc Sports Nutr. 2015;12:30.

27. Sale C, Saunders B, Harris RC. Effect of beta-alanine supplementation on muscle carnosine concentrations and exercise performance. Amino Acids. 2010;39(2):321-33

28. Quesnele JJ, Laframboise MA, Wong JJ, Kim P, Wells GD. The effects of beta-alanine supplementation on performance: a systematic review of the literature. Int J Sport Nutr Exerc Metab. 2014;24(1):14-27.

29. Caruso J, Charles J, Unruh K, Giebel R, Learmonth L, Potter W. Ergogenic effects of $\beta$-alanine and carnosine: proposed future research to quantify their efficacy. Nutrients. 2012;4(7):585-601.

30. Stellingwerff T, Decombaz J, Harris RC, Boesch C. Optimizing human in vivo dosing and delivery of $\beta$-alanine supplements for muscle carnosine synthesis. Amino Acids. 2012;43(1):57-65. 
31. Culbertson JY, Kreider RB, Greenwood M, Cooke M. Effects of betaalanine on muscle carnosine and exercise performance: a review of the current literature. Nutrients. 2010;2(1):75-98.

32. Hobson RM, Saunders B, Ball G, Harris RC, Sale C. Effects of $\beta$-alanine supplementation on exercise performance: a meta-analysis. Amino Acids. 2012;43(1):25-37.

33. Baguet A, Bourgois J, Vanhee L, Achten E, Derave W. Important role of muscle carnosine in rowing performance. J Appl Physiol. 2010; 109(4):1096-101

34. Saunders B, Sunderland C, Harris RC, Sale C. $\beta$-alanine supplementation improves YoYo intermittent recovery test performance. J Int Soc Sports Nutr. 2012;9(1):39.

35. Furst T, Massaro A, Miller C, Williams BT, LaMacchia ZM, et al. $\beta$-Alanine supplementation increased physical performance and improved executive function following endurance exercise in middle aged individuals. J Int Soc Sports Nutr. 2018;15(1):32.

36. Kim KJ, Song HS, Yoon DH, Fukuda DH, Kim SH, et al. The effects of 10 weeks of $\beta$-alanine supplementation on peak power, power drop, and lactate response in Korean national team boxers. J Exerc Rehabil. 2018;14(6):985-92.

37. Dolan E, Swinton PA, Painelli VS, Stephens Hemingway B, Mazzolani $\mathrm{B}$, et al. A systematic risk assessment and meta-analysis on the use of oral $\beta$-alanine supplementation. Adv Nutr. 2019;10(3):452-63.

38. Burke LM, Pyne DB. Bicarbonate loading to enhance training and competitive performance. Int J Sports Physiol Perform. 2007;2(1):93-7.

39. Wang Y, He F, Wang J, Hu Q. Comparison of effects of sodium bicarbonate and sodium carbonate on the hydration and properties of Portland cement paste. Materials. 2019;12(7).

40. Krustrup P, Ermidis G, Mohr M. Sodium bicarbonate intake improves high-intensity intermittent exercise performance in trained young men. J Int Soc Sports Nutr. 2015;12:25.

41. Wilde BR, Ye Z, Lim TY, Ayer DE. Cellular acidosis triggers human MondoA transcriptional activity by driving mitochondrial ATP production. Elife. 2019 Feb 5;8. pii: e40199.

42. Burke LM. Practical considerations for bicarbonate loading and sports performance. Nestle Nutr Inst Workshop Ser. 2013;75:15-26.

43. Wu CL, Shih MC, Yang CC, Huang MH, Chang CK. Sodium bicarbonate supplementation prevents skilled tennis performance decline after a simulated match. J Int Soc Sports Nutr. 2010;7:33.

44. Lopes-Silva JP, Da Silva Santos JF, Artioli GG, Loturco I, Abbiss C, et al. Sodium bicarbonate ingestion increases glycolytic contribution and improves performance during simulated taekwondo combat. Eur J Sport Sci. 2018;18(3):431-40.

45. Price MJ, Singh M. Time course of blood bicarbonate and $\mathrm{pH}$ three hours after sodium bicarbonate ingestion. Int J Sports Physiol Perform. 2008;3(2):240-2.

46. McNaughton L, Backx K, Palmer G, Strange N. Effects of chronic bicarbonate ingestion on the performance of high-intensity work. Eur J Appl Physiol Occup Physiol. 1999;80(4):333-6

47. Durkalec-Michalski K, Zawieja EE, Podgórski T, Zawieja BE, Michałowska $\mathrm{P}$, et al. The effect of a new sodium bicarbonate loading regimen on anaerobic capacity and wrestling performance. Nutrients. 2018;10(6):E697

48. Lancha Junior AH, Painelli Vde S, Saunders B, Artioli GG. Nutritional strategies to modulate intracellular and extracellular buffering capacity during high-intensity exercise. Sports Med. 2015;1:71-81.

49. Clements WT, Lee SR, Bloomer RJ. Nitrate ingestion: a review of the health and physical performance effects. Nutrients. 2014;6(11):522464

50. Domínguez R, Cuenca E, Maté-Muñoz JL, García-Fernández P, SerraPaya N, et al. Effects of beetroot juice supplementation on cardiorespiratory endurance in athletes. A Systematic Review. Nutrients. 2017; 9(1):E43

51. Lundberg JO, Weitzberg E, Gladwin MT. The nitrate-nitrite-nitric oxide pathway in physiology and therapeutics. Nat Rev Drug Discov. 2008;7(2):156-67.

52. Jones AM. Influence of dietary nitrate on the physiological determinants of exercise performance: a critical review. Appl Physiol Nutr Metab. 2014;39(9):1019-28.

53. Vanhatalo A, Fulford J, Bailey SJ, Blackwell JR, Winyard PG, et al. Dietary nitrate reduces muscle metabolic perturbation and improves exercise tolerance in hypoxia. J Physiol. 2011;589(22):5517-28.

54. Cuenca E, Jodra P, Pérez-López A, González-Rodríguez LG, Fernandes da Silva S, et al. Effects of beetroot juice supplementation on performance and fatigue in a 30-s all-out sprint exercise: a randomized, double-blind cross-over study. Nutrients. 2018;10(9):E1222.

55. Lansley KE, Winyard PG, Bailey SJ, Vanhatalo A, Wilkerson DP, et al Acute dietary nitrate supplementation improves cycling time trial performance. Med Sci Sports Exerc. 2011;43(6):1125-31.

56. Thompson C, Vanhatalo A, Jell H, Fulford J, Carter J, et al. Dietary nitrate supplementation improves sprint and high-intensity intermittent running performance. Nitric Oxide. 2016; 61:55-61. 
57. Wylie LJ, Mohr M, Krustrup P, Jackman SR, Ermıdis G, et al. Dietary nitrate supplementation improves team sport-specific intense intermittent exercise performance. Eur J Appl Physiol. 2013;113(7):1673-84.

58. Hoon MW, Jones AM, Johnson NA, Blackwell JR, Broad EM, et al. The effect of variable doses of inorganic nitrate-rich beetroot juice on simulated 2,000-m rowing performance in trained athletes. Int J Sports Physiol Perform. 2014;9(4):615-20.

59. Muggeridge DJ, Howe CC, Spendiff O, Pedlar C, James PE, et al. A single dose of beetroot juice enhances cycling performance in simulated altitude. Med Sci Sports Exerc. 2014;46(1):143-50.

60. Cermak NM, Gibala MJ, van Loon LJ. Nitrate supplementation's improvement of $10-\mathrm{km}$ time-trial performance in trained cyclists. Int J Sport Nutr Exerc Metab. 2012;22(1):64-71.

61. Wilkerson DP, Hayward GM, Bailey SJ, Vanhatalo A, Blackwell JR, et al. Influence of acute dietary nitrate supplementation on 50 mile time trial performance in well-trained cyclists. Eur J Appl Physiol. 2012; 112(12):4127-34.

62. Butts J, Jacobs B, Silvis M. Creatine use in sports. Sports Health. 2018;10(1):31-4.

63. Kreider RB, Kalman DS, Antonio J, Ziegenfuss TN, Wildman R, et al. International Society of Sports Nutrition position stand: safety and efficacy of creatine supplementation in exercise, sport, and medicine. J Int Soc Sports Nutr. 2017;14:18.

64. Yáñez-Silva A, Buzzachera CF, Piçarro IDC, Januario RSB, Ferreira LHB, et al. Effect of low dose, short-term creatine supplementation on muscle power output in elite youth soccer players. J Int Soc Sports Nutr. 2017;14:5.

65. Rawson ES, Miles MP, Larson-Meyer DE. Dietary supplements for health, adaptation, and recovery in athletes. Int J Sport Nutr Exerc Metab. 2018;28(2):188-99.

66. Volek JS, Rawson ES. Scientific basis and practical aspects of creatine supplementation for athletes. Nutrition. 2004;20(7-8):609-14.

67. Bazzucchi I, Felici F, Sacchetti M. Effect of short-term creatine supplementation on neuromuscular function. Med Sci Sports Exerc. 2009; 41(10):1934-41

68. Powers ME, Arnold BL, Weltman AL, Perrin DH, Mistry D, et al. Creatine supplementation increases total body water without altering fluid distribution. J Athl Train. 2003;38(1):44-50.

69. Bond P. Regulation of mTORC1 by growth factors, energy status, amino acids and mechanical stimuli at a glance. J Int Soc Sports Nutr. 2016;13:8
70. Farshidfar F, Pinder MA, Myrie SB. Creatine supplementation and skeletal muscle metabolism for building muscle mass- review of the potential mechanisms of action. Curr Protein Pept Sci. 2017;18(12): 1273-87.

71. Yoon MS. mTOR as a key regulator in maintaining skeletal muscle mass. Front Physiol. 2017;8:788.

72. Mielgo-Ayuso J, Calleja-Gonzalez J, Marqués-Jiménez D, CaballeroGarcía A, Córdova A, et al. Effects of creatine supplementation on athletic performance in soccer players: a systematic review and metaanalysis. Nutrients. 2019;11(4):E757.

73. Kreider RB. Effects of creatine supplementation on performance and training adaptations. Mol Cell Biochem. 2003;244(1-2):89-94

74. Guerrero-Ontiveros ML, Wallimann T. Creatine supplementation in health and disease. Effects of chronic creatine ingestion in vivo: downregulation of the expression of creatine transporter isoforms in skeletal muscle. Mol Cell Biochem. 1998;184(1-2):427-37.

75. Terjung RL, Clarkson P, Eichner ER, Greenhaff PL, Hespel PJ, et al American College of Sports Medicine roundtable. The physiological and health effects of oral creatine supplementation. Med Sci Sports Exerc. 2000;32(3):706-17.

76. Steenge GR, Simpson EJ, Greenhaff PL. Protein- and carbohydrate-induced augmentation of whole body creatine retention in humans. J Appl Physiol. 2000;89(3):1165-71.

77. Zawadzki KM, Yaspelkis BB 3rd, Ivy JL. Carbohydrate-protein complex increases the rate of muscle glycogen storage after exercise. J Appl Physiol. 1992;72(5):1854-

78. Antonio J, Ciccone V. The effects of pre versus post workout supplementation of creatine monohydrate on body composition and strength. J Int Soc Sports Nutr. 2013;10:36.

79. Candow DG, Vogt E, Johannsmeyer S, Forbes SC, Farthing JP. Strategic creatine supplementation and resistance training in healthy older adults. Appl Physiol Nutr Metab. 2015;40(7):689-94.

80. Harris RC, Söderlund K, Hultman E. Elevation of creatine in resting and exercised muscle of normal subjects by creatine supplementation. Clin Sci. 1992;83(3):367-74.

81. Robinson TM, Sewell DA, Hultman E, Greenhaff PL. Role of submaximal exercise in promoting creatine and glycogen accumulation in human skeletal muscle. J Appl Physiol. 1999;87(2):598-604.

82. Ramírez-Campillo R, González-Jurado JA, Martínez C, Nakamura FY, Peñailillo L, et al. Effects of plyometric training and creatine supplementation on maximal-intensity exercise and endurance in female 
soccer players. J Sci Med Sport. 2016;19(8):682-7.

83. Westerblad H, Bruton JD, Katz A. Skeletal muscle: energy metabolism, fiber types, fatigue and adaptability. Exp Cell Res. 2010;316(18):30939.

84. Brisson D, Vohl MC, St-Pierre J, Hudson TJ, Gaudet D. Glycerol: a neglected variable in metabolic processes? Bioessays. 2001;23(6):534-42.

85. van Rosendal SP, Osborne MA, Fassett RG, Coombes JS. Physiological and performance effects of glycerol hyperhydration and rehydration. Nutr Rev. 2009;67(12):690-705.

86. van Rosendal SP, Osborne MA, Fassett RG, Coombes JS. Guidelines for glycerol use in hyperhydration and rehydration associated with exercise. Sports Med. 2010;40(2):113-29.

87. Coutts A, Reaburn P, Mummery K, Holmes M. The effect of glycerol hyperhydration on olympic distance triathlon performance in high ambient temperatures. Int J Sport Nutr Exerc Metab. 2002;12(1):10519.

88. Wagner DR. Hyperhydrating with glycerol: implications for athletic performance. J Am Diet Assoc. 1999;99(2):207-12.

89. Lyons TP, Riedesel ML, Meuli LE, Chick TW. Effects of glycerol-in- duced hyperhydration prior to exercise in the heat on sweating and core temperature. Med Sci Sports Exerc. 1990;22(4):477-83.

90. van Rosendal SP, Strobel NA, Osborne MA, Fassett RG, Coombes JS. Performance benefits of rehydration with intravenous fluid and oral glycerol. Med Sci Sports Exerc. 2012;44(9):1780-90.

91. Wingo JE, Casa DJ, Berger EM, Dellis WO, Knight JC, et al. Influence of a pre-exercise glycerol hydration beverage on performance and physiologic function during mountain-bike races in the heat. J Athl Train. 2004;39(2):169-75.

92. Montner P, Stark DM, Riedesel ML, Murata G, Robergs R, et al. Preexercise glycerol hydration improves cycling endurance time. Int J Sports Med. 1996;17(1):27-33.

93. Siegler JC, Mermier CM, Amorim FT, Lovell RJ, McNaughton LR, et al. Hydration, thermoregulation, and performance effects of two sport drinks during soccer training sessions. J Strength Cond Res. 2008; 22(5):1394-401.

94. Murray R, Eddy DE, Paul GL, Seifert JG, Halaby GA. Physiological responses to glycerol ingestion during exercise. J Appl Physiol. 1991; 71(1):144-9. 